\title{
Emergindo de onde e para onde? "Países emergentes" e a possibilidade de configuração de uma nova ordem mundial
}

\author{
Emerging from where and to where? \\ "Emerging Countries" and the possibility of configuration a \\ new world order
}

\author{
Ana Elisa Saggioro Garcia Muller \\ Doutora em Relações Internacionais pela Pontifícia Universidade Católica do Rio de Janeiro (PUC - Rio) \\ Pesquisadora do BRICS Policy Center (BPC) \\ anasaggioro@gmail.com
}

\begin{abstract}
Resumo: Questionar a perda de poder dos EUA e a ascensão de países com economias ditas "emergentes" como possíveis novos pólos de poder, se tornaram senso comum em debates políticos e na mídia. A atual ascensão de países ditos "emergentes" configuraria perspectiva de ordem não-hegemônica ou contra-hegemônica? tais países, e suas diferentes forças sociais, reproduzem a lógica de acumulação capitalista, levando a um novo ciclo de expansão do capital global? Este ensaio problematiza a noção de mudança na ordem mundial a partir de diferentes abordagens e perspectivas político-teóricas. Busca-se contribuir ao refinamento dos instrumentos de reflexão e análise para ir além do senso comum, na tentativa de desconstrução de consensos que apresentam supostas "necessidades" sobre crescimento econômico e caminhos para o "desenvolvimento" que ofuscam indagações sobre para quê e para quem crescer e se desenvolver. Argumenta-se pela necessidade de atentar para o papel das forças sociais na construção de possível contra-hegemonia.
\end{abstract}

Palavras chave: Hegemonia. Imperialismo. BRICS. Teoria crítica.

\begin{abstract}
Questioning the loss of U.S. power and the rise of economies "emerging" as potential new poles of power, have become common sense in political debates and in the media. The current rise of countries called "emergent" would configure a perspective to non-hegemonic and counter-hegemonic order? such countries and their different social forces reproduce the logic of capitalist accumulation, leading to a new cycle of expansion of global capital? This essay discusses the notion of change in the world order from different perspectives and approaches to political theory. We seek to contribute to the refinement of the tools of reflection and analysis to go beyond common sense, in an attempt to deconstruct the present consensus that supposed "needs" on economic growth and paths for the "development" that obscure questions about why and for whom grow and develop. It is argued by the need to pay attention to the role of social forces in building counter-hegemony can.
\end{abstract}

Keywords: Hegemony. Imperalism. BRICS. Critical theory

Originais recebidos em: 21/05/2012

Aceito para publicação em: 25/09/2012

(c) EY No ND Este trabalho está licenciado sob uma Licença Creative Commons Atribuição-Uso NãoComercial-Vedada a criação de obras derivadas 3.0 Unported License. 


\section{Introdução}

Em que medida os EUA estão perdendo poder e posição na ordem mundial? Em que medida a China, juntamente com outros países com economias chamadas "emergentes" estão desafiando a posição dominante dos EUA e Europa, e indicam um novo pólo de poder no futuro? Esses questionamentos se tornaram comuns nos debates políticos e meios de comunicação no final da primeira década do século XXI. A década foi encerrada com uma profunda crise da economia capitalista, gerada pela sobreacumulação financeira, gerando excesso de capital excedente nos países centrais. Ela reflete também uma crise ambiental e climática, uma crise social e de acirramento das desigualdades, de paradigmas de civilização, e da "guerra sem fim" (WOOD 2005), com objetivos inalcançáveis e contra inimigos difusos, criados pela própria civilização ocidental contra um "Oriente" sobre o qual ela constrói sua "superioridade". Crises indicam também certo esgotamento de ciclos e modelos de acumulação e, com isso, oportunidades de mudança. Mas o que entendemos por mudança na ordem mundial? Quais são as ferramentas que podem nos ajudar na reflexão mais profunda sobre mudanças, possibilitando romper com certos consensos construídos, e compreender diferentes formas, espaços, tempos e agentes de transformação?

As principais correntes teóricas das Relações Internacionais (realismo e institucionalismo) têm um viés conservador, no sentido de elaborar, a partir de verificações empíricas, mecanismos e princípios para o melhor funcionamento das relações em uma estrutura previamente dada, não problematizando seu surgimento histórico e, portanto, não contemplando uma transformação radical da ordem. Busca-se explicar acomodações e ajustes dentro de uma estrutura que não é questionada. Em geral, essas teorias vão partir de fatos particulares para concluir tendências gerais, que são transformadas em regularidades tipo-lei. Elas separam diferentes áreas (economia, política, organizações internacionais, etc.) e conseguem, de forma eficiente, delimitar e fixar elementos, explicando efeitos causais que levam a determinados resultados no sistema internacional. Mecanismos e princípios detectados por elas em determinadas estruturas históricas perdem sua contextualização em tempo e espaço, ao se transformarem em tendências gerais do sistema internacional, que são repetidas/repetitivas, ou seja, observáveis e, mais importante, previsíveis.

Cox (1981/2000) denominou essas teorias de "solução de problemas", uma vez que buscam solucionar problemas dentro de determinada ordem social e política, que é Em Debat: Rev. Dig., ISSNe 1980-3532, Florianópolis, n. 7, p. 4-27, jan-jul, 2012. 
constante. Tais teorias interessam, segundo Cox, aos que se beneficiam dessa ordem. Metodologicamente, elas tentam expressar variáveis, fixas ou não, livres de valorização, ou seja, objetivas e distantes do sujeito que as analisa. Ao neorealismo e ao institucionalismo neoliberal, Cox também agregou a vertente do marxismo que elaborou determinantes econômicas causais para vários fenômenos sociais. Tudo que é sólido, no entanto, se dissolve no ar. E frente à solidez dessas teorias, outras buscaram desvendar suas contradições e compreender transformações na ordem social e política.

Essa compreensão requer, como primeiro passo, entender certos fenômenos causais explicados pelas teorias de solução de problemas, mas contextualizando-os em sua estrutura histórica específica. Questiona-se, primeiramente, como dada estrutura, para, então buscar elementos sobre como ela pode se transformar. Entende, portanto, as contingências do tempo, elementos do passado no presente, elementos do presente que indicam a transformação, negando, assim, a possibilidade de um presente constante, funcional àqueles no poder. Princípios e mecanismos têm múltiplos efeitos, que impactam de formas diversas diferentes atores e forças sociais, e essa complexidade é analisada em sua totalidade. Portanto, as chamadas "teorias críticas" procuram compreender o todo, com sua complexidade e contradições. Elas buscarão analisar essa totalidade em seu movimento, e não de forma estática, preocupando-se em vislumbrar "de cima para baixo e de baixo para cima" a realidade social, de modo a expor as contradições de certos fenômenos e visões de mundo, e quem é incluído e excluído destes. Ao desvendar as contradições, é possível verificar como certos consensos foram construídos e desconstruídos - por quem, para quem e de que forma - iluminando, assim, possibilidades de pensar outras formas de mundo, outros imaginários e outras realidades sociais que estão em constante reconstrução. A teoria crítica vai identificar, portanto, onde certos consensos escondem conflitos. Para Cox, é partir desses conflitos, nos quais se contesta dada hegemonia de forças sociais dominantes, que impulsionamos transformações (Ibid., p. 1540-46).

A interação entre idéias, capacidades materiais e instituições constituem estruturas em determinados períodos históricos. Essas estruturas históricas irão compor formas específicas de Estados, forças sociais e determinadas ordens mundiais. Esses três elementos influenciam um ao outro de forma dinâmica (Ibid., p. 1548-51). Com isso, as relações "inter-nacionais" não podem ser vistas a partir do Estado como ator unitário, conciso, cujo poder reflete suas capacidades materiais e bélicas, que é constrangido pelo sistema de forma mecânica, conforme concebem os neo-realistas. Estados são Em Debat: Rev. Dig., ISSNe 1980-3532, Florianópolis, n. 7, p. 4-27, jan-jul, 2012. 
entendidos por Cox de forma ampliada e dinâmica (sociedade política e civil). A ordem mundial pode se transformar na interação entre diferentes formas de Estado e forças sociais. Uma ordem hegemônica deve ser, portanto, contextualizada historicamente. Para tanto, é necessário buscar explicações no âmbito das forças sociais moldadas pelas relações sociais de produção ${ }^{1}$. Elas são o ponto de partida para pensar sobre possíveis futuros, podendo combinar diferentes configurações da ordem mundial. Numa ordem não hegemônica, os centros de poder entrariam em conflito, com a ascendência de coligações neo-mercantilistas, ligadas a capitais nacionais e trabalhadores estabelecidos, com formas de Estados corporativistas industriais nacionais. Já uma ordem contrahegemonia estaria baseada no "terceiro mundo", iria contra a dominação dos países centrais, objetivando um desenvolvimento autônomo (COX 1981, p. 1562-4).

Podemos observar aqui um diálogo implícito com Wallerstein (1974), para quem a semi-periferia buscava mudar seu papel econômico, em diferentes estágios históricos, através de estratégias mercantilistas, buscando industrializar-se e tornar-se centro ${ }^{2}$. Em que medida a hegemonia pode ser desafiada por países nos quais as classes dominantes estão comprometidas com o próprio projeto hegemônico? A atual ascensão de países chamados "emergentes", não-ocidentais, "semi-periféricos", configurariam uma perspectiva de ordem não-hegemônica, ou esses países, e suas diferentes forças sociais, reproduziriam a lógica de acumulação capitalista, levando assim a um novo ciclo de expansão do capital global? Ao longo desse ensaio apresentaremos diferentes abordagens e perspectivas político-teóricas, a fim de contribuir ao refinamento dos instrumentos de reflexão e análise sobre mudanças na ordem mundial. Buscamos assim instrumentos que permitam refletir sobre certos consensos, para que possamos

\footnotetext{
${ }^{1}$ Cox argumenta que prefere usar o termo "forças sociais" ao invés de classes, pois esta refletia a natureza de sociedades industriais, que hoje são mais complexas e diferenciadas. Para ele, hoje, trabalhadores estabelecidos podem ser representados como "privilegiados" frente às massas desempregadas e em empregos precários e informais. Em algumas sociedades, populações indígenas não se encaixariam no conceito de "proletariado". O termo "forças sociais" é explicitamente vago, forçando-nos a averiguar historicamente e em cada sociedade quem são as populações expropriadas e os agentes de transformação. Estes não estão previamente definidos, serão construídos em determinados processos de lutas emancipatórias. Ver COX 2009.

${ }_{2}^{2}$ Para Wallerstein, o capitalismo é economia do sistema de Estados moderno ("sistema mundo"), que se divida em posições estruturais de centro, semperiferia e periferia. Os Estados jogam um papel estrutural na economia mundial, e as forças de mercado mundial acentuam e institucionalizam as diferenças entre entres, tornando difícil superá-las. A posição da semi-periferia, e sua burguesia dependente, teria um papel mais político que econômico, para fazer o capitalismo funcionar de forma fluida, pois ela mediava (assim como as classes médias nas sociedades capitalistas) entre dois pólos opostos, contribuindo para a estabilidade política (e por sua vez econômica) do sistema como um todo. Ela assume um duplo papel, de explorada e exploradora, fazendo com que o centro não sofra uma oposição unificada. Ver WALLERSTEIN 1974, p. 403-5.

Em Debat: Rev. Dig., ISSNe 1980-3532, Florianópolis, n. 7, p. 4-27, jan-jul, 2012.
} 
desconstruí-los, descortinando conflitos, lutas e contradições, abrindo o imaginário para possíveis novas realidades.

Iniciaremos com uma breve apresentação sobre quem são os chamados "emergentes", para logo discorrermos sobre diferentes perspectivas: aquelas que contemplam ajustes e acomodações para manutenção da ordem, aquelas que vêem mudanças e descolamentos do centro de acumulação, podendo significar uma transição do próprio capitalismo e, por fim, aquelas que analisam mudanças e configurações históricas que desembocam no aprofundamento das relações sociais e entre Estados no capitalismo atual. Argumentaremos que é necessário atentar para o papel das forças sociais na construção de uma possível contra-hegemonia. Cox e Poulantzas, ambos baseados em Gramsci, nos alertam para a complexidade de construções sociais como os Estados. Para compreendermos processos como hegemonia e contra-hegemonia em sua totalidade, temos que examinar não somente Estados na sua forma simples, mas reconhecer o papel das forças sociais dominantes, dominadas, e das lutas sociais que se dão nas diversas esferas sociais, locais, nacionais e transnacionais.

\section{Os chamados BRICS}

Brasil, Índia, China, Rússia e África do Sul se inserem no grupo dos chamados "países emergentes", cujo crescente protagonismo na política e na economia mundial tem gerado análises que apontam para uma transformação da ordem global. Os chamados "BRICS" têm sido utilizados no discurso político para qualificar algumas das principais forças políticas dessa nova ordem. O termo surgiu em 2001 com o relatório do banco de investimentos estadunidense Goldman Sachs. O criador do conceito prevê que os "tijolos" da economia mundial Brasil, Rússia, Índia e China terão uma economia superior à dos países do G6, em 2050. Dados e simulações reforçariam o potencial de seus mercados, a complementaridade econômica, o protagonismo político dos países do bloco e, possivelmente, uma aliança entre eles. ${ }^{3}$ De fato, a difusão de atividades econômicas e investimentos dos países centrais para a periferia se deu de forma acelerada no período do pós-guerra, mais especificamente a partir da década de 1970, após a reconstrução da Europa e do Japão. Os países que hoje compõem os BRICS (com diferenciações e especificidades culturais e históricas entre eles) puderam

\footnotetext{
${ }^{3} \mathrm{http}: / / \mathrm{www}$ 2.goldmansachs.com/ideas/brics/BRICs-and-Beyond.html http://www2.goldmansachs.com/ideas/brics/index.html Em Debat: Rev. Dig., ISSNe 1980-3532, Florianópolis, n. 7, p. 4-27, jan-jul, 2012.
} 
absorver a difusão dessas atividades com capacidade política e econômica diferenciada dos demais países periféricos, tornando-se novos pólos de crescimento. Se em 1950, os países BRICS representavam juntos (incluindo, nessa época, toda a região da URSS) $21 \%$ do PIB/Poder Paritário de Compra no mundo, frente $28 \%$ dos EUA e $26 \%$ da Europa Ocidental, em 2008 (no ano de início da crise econômica mundial), os BRICS juntos já representam 29,5\% do PIB/PPC mundial, frente 18,5\% dos EUA e $17 \%$ da Europa Ocidental (BRICS POLICY CENTER 2011).

Para além da necessidade de questionarmos o status de Rússia e China como "futuras" potências dessa ordem, uma vez que estas configuraram as principais potências do bloco socialista durante a guerra fria (já tendo, no âmbito das Nações Unidas e do ponto de vista militar, um status diferenciado), existem muitos debates sobre a pertinência de agrupar países tão distintos em um mesmo bloco, que não caberiam no escopo deste trabalho. A abstração e construção discursiva dos BRICS, na formulação do banco, tem o sentido de identificar novos espaços e oportunidades de mercado para a reprodução expandida do capital, parecendo estar, desse modo, aquém de indicar transformações concretas nas estruturas de poder. A tentativa de agentes econômicos globais de buscarem, na inserção de países antes denominados "semiperiféricos", estratégias privadas de mercado não confere uma novidade e acompanha o processo de transnacionalização econômica desses países, que se acelerou na década de 1990.

Da mesma forma que a introdução do neoliberalismo tomou um formato de "receituário", conhecido como "Consenso de Washington", e foi imposto como condição de empréstimo e renegociação de dívidas em programas de ajuste estrutural das instituições financeiras multilaterais, os chamados "working papers" do banco Goldman Sachs também expõem determinados caminhos a serem seguidos pelos países para que continuem crescendo e, assim, se tornem economicamente mais fortes que o G6 nas próximas décadas. Essas medidas referem-se ao ritmo de crescimento econômico, políticas de estabilização fiscal e macroeconômica, eficiência das instituições domésticas, manutenção de um mercado aberto para comércio e "amigável" a investidores externos, e capacitação da mão de obra, qualificando trabalhadores para esse crescimento (WILSON; PURUSHOTHAMAN 2003). Segundo os membros do banco, tais medidas são necessárias para que suas previsões se realizem, e os BRICS alcancem ("catch up") os países desenvolvidos. Podemos observar a formulação, uma vez mais, de "receitas" homogeneizantes, expostas como "necessidades" para alcançar a Em Debat: Rev. Dig., ISSNe 1980-3532, Florianópolis, n. 7, p. 4-27, jan-jul, 2012. 
"modernização", que têm efeito disciplinador sobre as políticas públicas. Não são consideradas especificidades, condições sociais das populações, setores específicos, diferenças históricas, geográficas, culturais, etc. Busca-se, repetitivamente, a produção de um consenso sobre o crescimento econômico como um "bem em si mesmo". Esse crescimento se vincula a modelos de desenvolvimento que, nesses países, muitas vezes, estão baseados na expropriação e exploração de trabalhadores/as e do meio-ambiente, de forma flagrante.

A crise econômica mundial iniciada nos EUA em 2007 foi, para muitos, um evento que gerou impulso e aceleração do protagonismo desses países emergentes, o qual, por sua vez, levou a diferentes reações. Para aqueles que falam do centro hegemônico e buscam "aflitamente" manter sua posição de poder, os EUA devem buscar meios de integrar esses países nas instâncias internacionais, de modo a dividir o peso e a responsabilidade de saídas da crise, mas de forma cuidadosa, sem alterar as regras, normas e valores existentes. Não deve haver "ilusões" quanto às intenções desses países, que, com frequência, se opõem aos valores estadunidenses. Seriam potenciais rivais e devem ser contidos nas suas aspirações crescentes por mais poder e participação (PATRICK 2010). Em outras palavras, se esses países não assumirem responsabilidade "dentro da ordem", não será possível reformar as estruturas de governança global, mantendo a ordem liberal ocidental que os EUA criaram e defenderam (Ibid., p. 44) ${ }^{4}$.

Do lado oposto, vozes mais otimistas percebem a crise como "catálise" de mudanças das relações hierárquicas de poder e possibilidade de reforma das instituições internacionais. O G20 teria se tornado o fórum central de coordenação entre os principais países (e não mais o G8), no qual os "emergentes" e "intermediários" buscam acertar uma estratégia de mudança "from within". Se, antes da crise, os países emergentes buscavam criar fóruns e articulações entre si, alternativos aos dos países centrais, após a crise, sua estratégia teria mudado para uma ação diplomática mais

\footnotetext{
4 Patrick chega a afirmar que o "cenário ideal" seria que Washington formulasse um acquis communautaire nos moldes da União Européia para que os países ascendentes abraçassem as regras, princípios e normas ocidentais existentes. Mas estes estariam interessados em alterar tais normas e não adotá-las por completo (Ibid., p. 47). Os EUA não teriam outra escolha senão contar com países emergentes para enfrentar os desafios globais após a crise econômica, porém não haveria garantia nem formas de controle sobre as escolhas desses países. Ele aponta para a necessidade de "ajustes psicológicos" dos tomadores de decisão estadunidenses, que há meio século comandaram a política mundial e usaram instituições e regras "ao seu bel prazer". Agora, os EUA deveriam construir uma ordem verdadeiramente multilateral, de modo a acomodar os emergentes, dando-lhes obrigações, e evitando que estes utilizem as regras e instituições de forma voluntarista. Ver ibid., p. 53.

Em Debat: Rev. Dig., ISSNe 1980-3532, Florianópolis, n. 7, p. 4-27, jan-jul, 2012.
} 
direta, advogando por reformas na arquitetura global. O resultado esperado dessa nova estratégia seria uma difusão do poder e da influência internacional, que pode levar a uma ordem mais diversificada, e uma estrutura de governança descentralizada, com múltiplos centros e níveis. Isto já estaria sendo alcançado com a reforma do Fundo Monetário Internacional (CHIN 2010).

\section{Ajustes e acomodações dentro da ordem}

Conforme mencionado, as principais correntes teóricas das Relações Internacionais, o realismo e o institucionalismo, preocuparam-se em explicar mecanismo de estabilidade e manutenção da ordem, e não sua transformação. Nesse sentido, mudanças são ajustes e acomodações dentro da própria ordem. Enquanto realistas tinham no mecanismo da balança de poder a principal fonte de ajustes mútuos na competição por poder no sistema, os institucionalistas se centraram na capacidade das instituições de gerar cooperação entre Estados para maximizar seus interesses, influenciando também o comportamento destes.

Gilpin introduziu certa noção de mudança na teoria "estática" do realismo com sua teoria da guerra hegemônica, porém essa noção nos parece limitada. ${ }^{5}$ Ele defende a necessidade de um hegemon para manter a estabilidade do sistema, sendo necessário, também na economia, uma liderança forte e estabelecida que possa promover a cooperação e impor regras que sustentem o sistema capitalista de forma "justa". ${ }^{6}$ Ele aponta para o relativo declínio econômico dos EUA e, consequentemente, de sua liderança. A década de 1990 intensificou as relações de interdependência com a crescente integração de mercados financeiros e de processos industriais através da globalização. Essa "revolução financeira" vem aumentando o capital disponível e

\footnotetext{
${ }^{5}$ Gilpin é reconhecido nas Relações Internacionais por ter introduzido elementos de mudança na estrutura internacional através de ciclos de guerras hegemônicas. Conforme veremos no capítulo 4 , estes são ciclos padronizados, que seguem as mesmas etapas de ascensão, contestação, guerra e nova hegemonia, num movimento intercalado, porém repetitivo, entre guerra e paz hegemônica. Ele trata hegemonia em termos racionalistas: relação custo-benefício para que o Estado até então dominante mantenha ou recupere sua posição de poder, e o Estado em ascensão use a oportunidade de crise para conseguir crescer. Seus ciclos hegemônicos indicam uma constância de desigualdades e estruturas hierárquicas, nas quais há ajustes, mas não rupturas. Seu conceito de mudança no sistema nos parece, portanto, limitado.

${ }^{6} \mathrm{O}$ autor se apóia na teoria de estabilidade hegemônica de Kindleberger (1973). Para este, a crise e a Grande Depressão dos anos 30 poderiam ter sido evitadas se a Inglaterra tivesse tido capacidade, e os EUA vontade política de exercer liderança Ambos foram incapazes de preservar o "bem público", a responsabilidade de estabilizar o sistema com políticas anti-cíclicas de movimento de capital e promoção do comércio internacional, gerando crescimento econômico $\mathrm{O}$ sistema econômico internacional precisaria assim de uma única liderança para manter sua estabilidade.
}

Em Debat: Rev. Dig., ISSNe 1980-3532, Florianópolis, n. 7, p. 4-27, jan-jul, 2012. 
acelerando o desenvolvimento econômico do Leste Asiático, ao mesmo tempo em que deixa a economia global mais vulnerável, tendo gerado diversas crises ao longo dos anos 90 e 2000. Os investimentos diretos estrangeiros tornaram as empresas multinacionais importantes vetores de fluxo de capital, comércio e a localização das indústrias, determinando o grau de bem-estar econômico dos países (GILPIN 2004, p. 41). As empresas multinacionais acabam sendo atores centrais não somente na economia, sua atuação tem, também, efeitos políticos, como já havia sido apontado pelo autor décadas atrás (GILPIN 1975).

Hoje, o autor vê uma transformação do sistema econômico e político mundial com a globalização econômica, a revolução tecnológica, as questões demográficas e a redistribuição de poder econômico do Ocidente industrializado para as economias de rápida industrialização na Ásia. Para ele, há um declínio relativo de poder econômico dos EUA para a China, em especial como efeito da transferência da produção (Ibid, 2004, p. 54). A migração de indústrias tradicionais, assim como de tecnologia avançada, para a China e Leste Asiático aconteceu com extrema rapidez para padrões históricos, intensificando a concorrência e acelerando a difusão de tecnologias sofisticadas através das empresas. Estas buscam aumentar a competitividade global combinando mão-deobra barata na Ásia e no Sul com técnicas de manufatura avançadas do Norte. Com isso, agrava-se o desafio dos EUA e das outras economias industrializadas frente ao enorme número de trabalhadores de baixos salários, que entram em concorrência com outros numa "rede mundial de trabalho". Em suma, a rápida industrialização da Ásia e Pacifico e o repentino surgimento de muitos países como exportadores de peso, teriam levado a uma redistribuição na balança internacional de poder e competitividade econômica (Ibid., p. 58-9).

Mas, segundo Gilpin, embora a ordem econômica internacional do pós-guerra esteja se diluindo, ainda não há acordo sobre regras e princípios básicos para uma nova ordem econômica mundial. Ainda não seria possível falar em ascensão de um novo hegemon. Ele enfatiza a primazia de fatores políticos sobre os econômicos: seria necessária a constituição das bases políticas para uma economia mundial estável (Ibid, p. 459). Essas bases são, para Gilpin, a possível retomada da capacidade e disposição de liderança dos EUA como "hegemon benevolente" para manter estabilidade e paz. Seria necessário preservar, para isso, sua presença militar na Europa e na Ásia, e evitar o protecionismo comercial e a regionalização de acordos que excluíssem os EUA, coordenando uma estratégia política com as demais economias (Ibid, p. 460-5). Em Debat: Rev. Dig., ISSNe 1980-3532, Florianópolis, n. 7, p. 4-27, jan-jul, 2012. 
Ikenberry (2001) busca explicar as acomodações na ordem a partir das instituições. Para ele, historicamente, "após a vitória" de uma guerra hegemônica, os Estados optaram por transformar seu poder abundante em uma ordem que assegurasse durabilidade. Esta depende da capacidade do hegemon de construir instituições e mecanismos que "aprisionem" (lock in) determinadas regras, normas, princípios e possibilidades de ação, condicionando escolhas futuras. Além disso, depende da habilidade de auto-restringir, estrategicamente, seu poder dentro dessas instituições, de modo que Estados menores ou mais fracos legitimem a ordem (IKENBERRY 2001, p. 37-41). Assim, o hegemon economiza custos de uso da força e de convencimento, uma vez que sua habilidade de restringir seu poder, com mecanismos institucionais, faz com que os outros Estados tenham limitadas possibilidades de contestar a própria ordem hegemônica. Combinada auto-restrição com mecanismos institucionais de "lock in", o autor sustenta que hegemons com caráter democrático foram capazes de construir ordens institucionais duráveis com um viés constitucional. Aqui é clara a referência à construção da hegemonia estadunidense após a Segunda Guerra Mundial, cuja base seria a própria democracia liberal americana. Princípios multilaterais, espaços para barganha e institucionalização de regras e normas com participação e consentimento dos demais países, tudo isso teria conferido à ordem estadunidense características de uma "hegemonia de acionistas", refletindo também características de suas instituições domésticas (IKENBERRY 2001b).

Ikenberry se aproxima de Keohane (1993), que buscou explicar o porquê de os regimes permanecerem, mesmo após o declínio da hegemonia. Os regimes fortes, construídos numa ordem hegemônica com viés constitucional, tendem a durar, porque os outros Estados vêem mais vantagens em permanecer no regime do que fora dele ${ }^{7}$. Ao contrário do que sustentam marxistas e realistas - os regimes e as instituições refletem o poder do mais forte no sistema - para estes institucionalistas, os regimes limitariam o excesso de poder.

\footnotetext{
${ }^{7}$ Os regimes internacionais, para Keohane, devem ser entendidos de forma ampla, como modelos de comportamento cooperativo regulados na política mundial. Regimes fortes se distinguem de regimes fracos por estabelecerem um comportamento ordenado e previsível, segundo padrões comuns aos participantes, enquanto que em regimes fracos as regras seriam interpretadas de forma diferenciada, e são freqüentemente rompidas (KEOHANE 1993, p. 112). O autor sustenta que a continua erosão da hegemonia americana influi diretamente no regime internacional de petróleo, mas não leva à desintegração do regime monetário de Bretton Woods, e afeta ainda menos o regime comercial com base no GATT, uma vez que neste os outros Estados viam mais vantagens mútuas. Dessa maneira, Keohane reinterpreta a "teoria da estabilidade hegemônica", diferenciando a estabilidade por áreas e regimes.

Em Debat: Rev. Dig., ISSNe 1980-3532, Florianópolis, n. 7, p. 4-27, jan-jul, 2012.
} 
A ascensão econômica de países não ocidentais tem levado a uma relativa contestação da ordem e a uma rivalidade com os EUA e Europa. Se, historicamente, desafios às potências hegemônicas podem levar a transformações e guerras, hoje existiriam, segundo Ikenberry/Wright (2008), canais e mecanismos de integração e incorporação de Estados emergentes em arranjos de governança da ordem anterior. A institucionalização impulsionada pelos EUA é mais difícil de ser derrubada, precisamente porque é mais acessível. Para os autores, a ordem institucional dá aos emergentes certa proteção, pois elas teriam estruturas flexíveis, sendo relativamente simples crescer nas suas hierarquias. Suas características, constrangimentos e incentivos apontariam para a acomodação e não transformação da ordem. Os emergentes teriam interesse em manter uma ordem estável e aberta, tendo incentivos de apoiar regras em favor dessa estabilidade e abertura (IKENBERRY;WRIGHT 2008, p. 5-6).

Os autores consideram, portanto, que as formas possíveis de transição na ordem atual são diferentes daquelas do passado, em especial a recorrência histórica de guerras hegemônicas ${ }^{8}$. O desenvolvimento de armas nucleares teria tornado difícil a chance de uma guerra hegemônica nos dias atuais. Eles afirmam que confrontar os EUA significaria confrontar todo um bloco aliado. Segundo Ikenberry/Wright, quanto mais a ordem hegemônica for baseada em instituições e regras, for aberta e consensual, quanto mais forem distribuídos os benefícios materiais da ordem, é mais provável que Estados emergentes assegurem seus interesses integrando-se à ordem, e não a desafiando (Ibid., p. 9). Além disso, os autores procuram demonstrar que os países emergentes não agem em bloco, tendo preferências e estratégias diferenciadas, de acordo com as instituições e regimes nos quais atuam. Eles consideram que as instituições e regimes, por terem regras universais, possibilitam a proteção dos emergentes contra ações discriminatórias dos EUA, servindo, portanto, para a restrição de poder do hegemon. Ao percorrer a via institucional e implementar políticas e ações unilaterais, os neoconservadores na administração da política externa americana estariam corroendo a própria forma de manutenção da hegemonia estadunidense (Ibid., p. 28).

Hurrel (2009) converge com a visão institucionalista de que os países emergentes almejam ascender dentro das hierarquias institucionais existentes. Com relação aos EUA, eles teriam a opção de balanceamento de poder, formando coligações para contrapor-se ao poder da potência, ou de "bandwagoning", ou seja, alinhar-se à

\footnotetext{
${ }^{8}$ Com exceção da China e da Rússia, as potências emergentes não teriam capacidade militar e seu crescimento econômico seria extremamente dependente do comércio e do investimento mundial.

Em Debat: Rev. Dig., ISSNe 1980-3532, Florianópolis, n. 7, p. 4-27, jan-jul, 2012.
} 
potência de forma pragmática. Segundo o autor, os países variam em suas estratégias, mas vêm praticando um "balanceamento brando". Os BRICs não têm capacidade de balancear militarmente os EUA, mas buscam equilibrar o sistema por meio de cooperação, entendimentos informais e colaboração em instituições, com o objetivo de complicar ou aumentar os custos das políticas dos EUA em instituições. Nesse sentido, usaram mecanismos não-militares para atrasar, frustrar e mitigar políticas agressivas e unilaterais dos EUA. Para Hurrel, a necessidade de conter o poder unilateral dos EUA compõe um elemento importante da política dos BRICs (HURREL 2009, p. 34-6).

\section{Mudanças na ordem mundial e deslocamento do centro de acumulação}

Wallerstein se destaca dentre aqueles que, desde a década de 1970, vislumbravam um declínio da hegemonia estadunidense. O período hegemônico revelase para o autor como um breve intervalo de tempo, no qual a potência tem simultaneamente vantagens financeiras, agro-industriais e de comércio acima dos demais países. Esse intervalo se encontra numa linha histórica fluida de rivalidades entre potências (WALLERSTEIN 1991). Com isso, ele afirma que, de 1945 a 1970, a hegemonia dos EUA foi inquestionável, mas a partir dos anos 1970, ela entra em declínio. No início do século XXI, Wallerstein afirma que os EUA, com as políticas unilaterais do governo Bush, buscaram recuperar sua posição, mas elas surtiram o efeito oposto, acelerando e aprofundando o declínio. Diversos eventos seriam sinal claro do colapso do poder americano, e o mundo teria adentrado uma divisão geopolítica de poder multilateral, com diferentes centros de poder, destacando-se a união da Ásia Oriental (WALLERSTEIN 2009).

Cox também destaca a ascensão de uma ordem mundial plural. A crise financeira de 2008 teria gerado um bloqueio no sistema, levando a que os Estados buscassem uma auto-organização. Essa auto-organização advém do fato de não haver um poder dominante que possa impor sobre outros uma forma determinada de saída da crise e reorganização do sistema. Cox aproxima-se, aqui,da noção de estabilidade hegemônica. Assim como "neurônios no cérebro" que se auto-organizam para superar um bloqueio, o sistema de Estados atual busca formas coletivas de regulação da economia global, uma vez que os EUA já não podem impor de forma efetiva sua força.

Diante disso, o problema passa a ser os possíveis graus de auto-organização e a 
mudança para um grupo maior de países, como o G20, demonstrando a necessidade de coordenação para a saída da crise econômica. Dessa forma, estaríamos num momento de perda de poder dos EUA, mas sem a ascensão de um novo poder hegemônico, podendo levar, assim, a uma ordem plural (COX 2009).

Dentro dessa ordem plural ou não hegemônica, a ousada tese de Arrighi (2008) aponta para uma releitura de Adam Smith para vislumbrar a possibilidade de surgimento de uma sociedade de mercado mundial, regulada pelos Estados. Para este autor, o comércio mundial, mesmo que baseado numa divisão desigual do trabalho que conduzia a uma especialização com base na exploração dos povos e seus recursos, levaria ao maior intercâmbio que complementasse as necessidades, beneficiando assim todas as civilizações. A "riqueza das nações" seria fruto do livre comércio mundial, mesmo que a "superioridade de força" dos Europeus permitisse que injustiças cometidas em terras distantes ficassem impunes. Segundo ele, ao longo do tempo, o comércio permitiria que outros povos se tornassem fortes e a Europa enfraquecesse, levando à igualdade de forças entre as diversas partes do mundo, tendendo assim a um maior respeito entre todos (SMITH apud ARRIGHI, p. 19). Smith tinha em mente o império britânico, e sua teoria sustentava ideologicamente a política de livre comércio inglês, cujo nível de produção era mais alto que seus "parceiros" comerciais. Com base na idéia inicial de Smith, Arrighi sustenta que "o fracasso do Projeto para o Novo Século NorteAmericano e o sucesso do desenvolvimento econômico chinês, tomados juntos, tornaram mais provável do que nunca (...) a concretização da idéia de Smith de uma sociedade mundial de mercado baseada em mais igualdade entre civilizações" (Ibid., p. 24).

Arrighi afirma que a "mão invisível" referida por Smith é o Estado, que deveria dominar de forma descentralizada, com mínima interferência burocrática (ARRIGHI 2009). Numa sociedade mundial de mercado, os países se relacionariam através de mecanismos de regulação estatal, portanto não auto-regulado. O mercado seria assim um "instrumento dos governos" para seu desenvolvimento (ARRIGHI 2008, p. 57). Com essa leitura de Smith, Arrighi interpreta que o Estado chinês utiliza os mecanismos de mercado em prol do seu "interesse nacional", inversamente de Estados capitalistas, nos quais o interesse do capital predomina sobre o interesse nacional. A China teria implantado reformas de maneira gradual, e teria seguido os conselhos do Banco Mundial em termos e condições que serviam ao seu interesse nacional, e não aos interesses do capital ocidental. O governo chinês garante a concorrência entre capitais Em Debat: Rev. Dig., ISSNe 1980-3532, Florianópolis, n. 7, p. 4-27, jan-jul, 2012. 
estrangeiros e nacionais, sem colocar trabalhadores para competir por salários. $\mathrm{O}$ desenvolvimento agrícola e a prioridade à formação do mercado interno pavimentaram o caminho para posterior industrialização e incrementação do comércio exterior, o que corresponderia ao que Adam Smith chamou de "caminho natural" do desenvolvimento (Ibid., p. 361-4).

Assim como para Wallerstein, Arrighi sustenta que o Projeto do Novo Século Norte-Americano do governo Bush após 2001, foi uma recusa em aceitar o declínio de seu poder e a tentativa de retomar um projeto de império global. Enquanto a crise econômica da década de 70 e a derrota dos EUA no Vietnam foram um sinal de crise do regime de acumulação (sinalizando o início do declínio da hegemonia), a crise econômica atual e o fracasso no Iraque podem significar uma crise terminal. A função do atual governo dos EUA seria a de administrar o declínio, acomodar as mudanças das relações de poder e não tentar "re-erguer" um império, lançando novas guerras como o governo anterior (ARRIGHI 2009). ${ }^{9}$

A criação de um novo ciclo hegemônico mundial com base na China é, contudo, incerta. Em trabalhos anteriores, Arrighi afirma que um Estado se torna hegemônico mundialmente (após a formação social hegemônica das classes dominantes no âmbito doméstico) quando pode reivindicar com credibilidade o papel de força-motriz da expansão universal do poder coletivo de seus dominantes com relação a outros Estados, assim como com relação às classes subalternas. Em situação de "caos sistêmico", um Estado em condições de satisfazer à demanda de saída do caos e estabelecimento de ordem apresenta-se como potencial hegemon (ARRIGHI 1993). O autor aponta que, assim como os três ciclos hegemônicos anteriores (holandês, britânico e norteamericano), a superioridade militar e a de recursos de um novo hegemon só seriam relevantes na medida em que exista pré-disposição e capacidade de lidar com eles de forma inteligente, o que vai depender das condições de caos sistêmico e demanda por ordem. Capacidades militares e econômicas não são per se condições suficientes. Como ciclos de acumulação, ciclos hegemônicos não ocorrem de forma padronizada. Arrighi afirma que os Estados hegemônicos dos sucessivos ciclos foram cada vez "menos capitalistas" que os anteriores, ao passo que o sistema inter-estatal se tornava mais

\footnotetext{
${ }^{9}$ Da mesma forma, Cox afirma que o papel dos outros países e do atual governo dos EUA seria de demonstrar e ajudar a população americana a compreender que os EUA não mais moldarão e determinarão o futuro do mundo. A população americana deverá passar por um árduo processo pedagógico para compreender as mudanças e transições de poder, para o qual ela não estaria preparada devido ao alto grau de ideologização de seu papel de liderança no mundo. Atuais líderes teriam que guiar e ajudar neste processo (COX 2009).

Em Debat: Rev. Dig., ISSNe 1980-3532, Florianópolis, n. 7, p. 4-27, jan-jul, 2012.
} 
capitalista, na medida em que mais Estados estavam sujeitos à lógica capitalista de poder. Nesse sentido, próximos hegemons seriam menos capitalistas nas suas estruturas internas de representação (Ibid., p. 183-185).

Aparentemente Arrighi preparava o caminho teórico para apontar um novo ciclo hegemônico no leste asiático. Mas o autor atenta para as especificidades e para a não repetição de padrões anteriores (diferenciando-se dos realistas). Arrighi observa que o capitalismo tem uma natureza fluida, adaptável e seu desenvolvimento se transforma historicamente dentro da estrutura do sistema inter-estatal. Para ele, não se pode dizer com certeza se a China é capitalista. Se assumirmos que ela é, não seria do mesmo tipo de períodos anteriores. É necessário, portanto, atentar para as especificidades (ARRIGHI 2009). O autor afirma que se a China vier a ser um hegemon global, teria características histórico-geográficas distintas de potências anteriores, e seus poderes cultural e econômico seriam muito mais relevantes que o poder militar. Uma nova época asiática, se existir, seria portadora de uma "hibridização fundamental" dos legados ocidentais e orientais (ARRIGHI 2008, p. 25).

\section{Mudanças na ordem com aprofundamento das relações de poder com base nos EUA}

A tese de Arrighi gerou polêmicas tanto para marxistas quanto para nãomarxistas. Essas visões críticas, que partem de perspectivas diferentes, chegam a conclusões próximas, que é o aprofundamento do poder estadunidense e das relações capitalistas. Fiori (2008) contesta as "profecias terminais" sobre o poder americano e trabalha, a partir de Braudel, as mudanças de tempo breve, ciclos econômicos e mudanças de "longa duração". Essa diferenciação o permite afirmar que, embora os EUA estejam sofrendo uma crise de sua liderança no tempo breve, além de algumas crises econômicas, isso não implicaria num colapso do poder americano como mudança de longa duração histórica. Teóricos dos "ciclos hegemônicos" confundiriam, segundo o autor, momentos conjunturais com mudanças estruturais. $\mathrm{O}$ que eles teriam pedido de vista é que o declínio relativo do poder do hegemon relacionado à reconstrução e ao crescimento econômico de outros Estados é parte da contínua grande transformação do sistema mundial, na qual a própria potência hegemônica tem papel decisivo, implicando em maior acumulação e poder dela mesma (FIORI 2008, p. 20-1). 
O autor propõe uma leitura do sistema mundial moderno como "universo em expansão", no qual as potências lutam por poder global. Essa expansão é precedida por um aumento da "pressão competitiva", provocada pelo expansionismo de uma potência líder, intensificando conflitos e culminando numa "explosão" ou alargamento das fronteiras desse "universo" ${ }^{10}$. Desde a década de 1970, estaríamos num momento de "explosão expansiva" do sistema mundial, com o aumento da "pressão competitiva" provocada pela estratégia expansionista e imperial dos EUA, e também pela multiplicação de Estados no sistema e pelo crescimento de poder e riqueza da China (Ibid., p. 24). A competição e a guerra, na busca por acumulação de poder e riqueza, não seriam sinal de colapso, mas sim partes inerentes ao processo expansionista do sistema, que ocorre de forma desordenada e desequilibrada, mas contínua. O hegemon precisa, muitas vezes, destruir regras e instituições, criadas por ele após a vitória de uma guerra hegemônica, para seguir se expandindo. Ao contrário do que sustentam teóricos da estabilidade hegemônica, não haveria paz nem hegemonia estável: o "universo em expansão" precisaria das guerras e crises para poder se "ordenar" e "estabilizar" de forma transitória, e seguir mantendo as estruturas e relações hierárquicas (Ibid., p. 31).

As economias nacionais e a moeda são instrumentos essenciais na acumulação de poder. As moedas internacionais foram sempre, ao longo da história, "as moedas nacionais dos Estados vencedores" (Ibid., p. 33). Para Fiori, a substituição do padrão dólar-ouro pelo "dólar flexível", apesar de ter tornado os EUA um devedor mundial, permitiu a eles exercerem um poder monetário e financeiro internacional sem precedentes. A crise dos anos 1970 levou a um aprofundamento do capitalismo e ao aumento do poder americano, transformando o sistema mundial numa ordem com características imperiais (Ibid., p. 18) ${ }^{11}$. Assim, o que para Arrighi, Wallerstein, entre

\footnotetext{
${ }^{10}$ Fiori expõe os momentos na história característicos dessa expansão: o primeiro, no século XIII (aumento da pressão competitiva provocado pela invasão dos mongóis, expansionismo das Cruzadas, guerras na península ibérica, com posterior nascimento de unidades territoriais soberanas e competitivas); o segundo, no século XVI (aumento da pressão competitiva causada pela expansão dos impérios Otomano e de Habsburgo, nascimento dos primeiros Estados soberanos e das potências ibéricas e, depois, dos Países Baixos); o terceiro, no século XIX (pressão competitiva provocada pelo expansionismo francês e inglês, o surgimento dos Estados americanos, logo depois, a corrida imperialista entre as potências européias que expandiram as fronteiras coloniais do sistema mundial moderno para a Ásia e a África) . Ver ibid., p. 23-4.

${ }^{11}$ Para o autor, o período inicial de construção da hegemonia, entre aprox. 1945 a 1967, transcendia o poder militar e estava mais baseado nas instituições. Porém, após a crise econômica, foram dadas as condições para um retomada conservadora de organização da ordem mundial. A partir de 1991, a política norte-americana tem sido "rigorosamente imperial (...) o comportamento econômico, cultural e diplomático dos Estados Unidos frente ao mundo tem sido o de um país que não apenas acredita, mas se comporta cada vez mais orientado por uma visão unipolar do mundo" Ver FIORI 1998, p. 126-7.

Em Debat: Rev. Dig., ISSNe 1980-3532, Florianópolis, n. 7, p. 4-27, jan-jul, 2012.
} 
outros, sinalizava o início do declínio da hegemonia estadunidense, para Fiori é parte necessária da acumulação de poder e riqueza da potência.

O autor aponta para o crescente dinamismo dos países emergentes, que reivindicam mudanças nas regras de "gestão" do sistema mundial e na distribuição desigual de poder. Contudo, esses países teriam mais diferenças que similitudes na sua inserção internacional, com a China distanciando-se progressivamente dos demais. Fiori relaciona o crescimento da China não com uma rivalidade, mas com o próprio expansionismo dos EUA. Entre eles haveria uma "relação siamesa": a China foi incluída no mercado e capital financeiro norte-americano, aumentou o poder do dólar e dos títulos de dívida do governo dos EUA e, assim, a capacidade de multiplicação de seu capital financeiro. O Estado chinês teria intermediado e usado a força da expansão americana a seu favor, iniciando assim uma estratégia de expansão do seu próprio poder relativo. Desse modo, a internacionalização americana, associada ao crescimento chinês, teria produzido "uma mudança estrutural de longa duração no sistema mundial", criando um novo "centro nacional de acumulação de poder e capital" (FIORI 2008, p. 67). Essa mudança não se dá, no entanto, no advento de uma guerra hegemônica. Se, de um lado, devemos nos preparar para uma nova corrida imperialista e a intensificação dos conflitos (nova "pressão competitiva"), não devemos esperar um "duelo final" entre China e EUA. Ao contrário, Fiori aponta para uma "fusão financeira" entre os dois países (Ibid., p. 68).

Panitch (2010) contesta a argumentação de Arrighi a partir de dois elementos fundamentais: seu conceito de "império informal americano" e a função do Estado nas relações capitalistas ${ }^{12}$. Sua leitura de Smith como teórico do mercado "como um instrumento de governo" tem implicações para o entendimento de Arrighi sobre o sistema econômico na China. Para Smith, a livre competição de mercado gerará benefícios econômicos para todos, sendo necessária, para o "bom funcionamento" do mercado (evitando a centralização e concentração), a operação da "mão invisível" que, na leitura de Arrighi, é a sua regulação pelo Estado. O Estado chinês faria esse papel,

\footnotetext{
${ }^{12}$ Uma terceira crítica, menos relevante para seu argumento geral, seria a base de Giovanni Arrighi na visão do sistema-mundo (seu livro é dedicado a Gunder Frank), que permitiria afirmar que a China não se encaixaria no que conhecemos como capitalismo. De acordo com essa concepção, que se baseia na divisão internacional do trabalho, o capitalismo é compreendido em termos da relação direta entre desenvolvimento capitalista no centro e subdesenvolvimento na periferia. Com uma divisão geográfica rígida entre Norte e Sul, Ocidente e Oriente, os teóricos baseados no sistema mundo dificilmente enxergam, segundo Panitch, a possibilidade de desenvolvimento capitalista na periferia, de modo que qualquer desenvolvimento econômico nela ocorrente não poderia ser entendido como capitalista no mesmo modelo que do centro (ibid.).

Em Debat: Rev. Dig., ISSNe 1980-3532, Florianópolis, n. 7, p. 4-27, jan-jul, 2012.
} 
utilizando o mercado e a livre-concorrência como instrumento de desenvolvimentos econômico, realizando, assim, seu "interesse nacional". Com isso, Panitch afirma que Giovanni Arrighi chega a uma definição de capitalismo que é central para seu livro: a principal diferença entre uma sociedade de mercado capitalista e não-capitalista seria o poder e a capacidade de capitalistas de impor seus interesses de classe às custas do interesse nacional (Ibid.). Para ele, Arrighi não problematiza termos como "interesse nacional" ou "interesse público" como construções ideológicas - notando que Smith escrevia no mesmo período das conquistas violentas, saques e expropriações em outros continentes - tratando-as como categorias objetivas. Além disso, essa definição ofusca a questão fundamental da lógica e dinâmica do capitalismo como sistema de produção, que é a relação entre produtores diretos com os meios de produção. Se a economia política marxista foi sistematicamente criticada por seu "determinismo econômico", Panitch afirma que a leitura de Arrighi sobre Smith sofreria de um "determinismo político".

Com isso, chegamos à questão fundamental para Panitch, que é a conceituação do Estado capitalista na sua relação com o capital. Conforme dito, o que determinaria o capitalismo para Arrighi seria, em última instância, a subordinação do Estado, que representaria o interesse "geral", aos interesses do capital, que seriam estreitos e particularistas. Para Panitch, no entanto, o que é determinante do Estado capitalista é a sua relação com a classe dominante como um todo, e não com setores específicos que são ou não colocados em concorrência uns com outros. É o Estado que garante as condições de concorrência no mercado capitalista, uma vez que ele mantém relativa autonomia frente às diferentes frações e setores da burguesia, mas de modo a garantir os interesses da classe capitalista como um todo ${ }^{13}$. O modo específico de organização do Estado capitalista, sua função de garantidor das relações de propriedade, reprodutor da relação capital-trabalho, e sustentador da acumulação estariam fora da conceitualização frágil de Arrighi. Para Panitch, a mercantilização da força de trabalho e a integração de trabalhadores numa sociedade mercantilizada, baseada na produção e consumo através

\footnotetext{
${ }^{13}$ Panitch se baseia na teoria do Estado capitalista de Poulantzas, para quem esse tem uma natureza dinâmica como espaço de relação entre classes, "condensando" as lutas sociais, que são inscritas na "materialidade" (instituições e burocracias) do Estado capitalista (POULANTZAS 2000). Sua relativa autonomia frente às diferentes frações da classe burguesa visa organizar uma "unidade conflituosa" do bloco do poder, de modo a garantir a realização do projeto hegemônico. Para isso é necessário desorganizar as classes subordinadas e fazer certas concessões a esta de modo a manter o consenso em torno deste projeto. Poulantzas é influenciado por Gramsci, para quem o Estado garante o "equilíbrio instável" de compromissos entre dominantes e dominados.
}

Em Debat: Rev. Dig., ISSNe 1980-3532, Florianópolis, n. 7, p. 4-27, jan-jul, 2012. 
de relações de troca, definem a natureza do desenvolvimento econômico na China contemporânea. Seguindo essa linha, torna-se difícil aceitar a noção não problematizada de "interesse nacional" numa sociedade de classes.

Panitch discorda de Arrighi sobre a perda de capacidade dos EUA de sustentar seu poder imperial, uma vez que isso confundiria contradições conjunturais ("sinais de crise") com contradições estruturais de longo prazo, conforme também expõe Fiori. O fluxo de capital da Ásia Oriental para os EUA, além de cobrir o déficit comercial, indica como os circuitos de capital global sustentam o poder estadunidense. Central para o conceito de Panitch do "império informal americano" é a construção do poder global estadunidense sem necessariamente estender sua soberania ou ocupar territorialmente outros Estados como estratégia prioritária. Mais importante foi a capacidade do Estado americano de penetração estrutural em antigos rivais e coordenação com outros Estados líderes capitalistas (PANITCH; GINDIN 2004). Com isso, foi possível garantir no período pós Segunda Guerra a estruturação de outros Estados independentes como Estados capitalistas, ou seja, que sustentem a acumulação de capital e protejam a propriedade privada (e não somente a propriedade do Estado imperial) dentro de seus territórios. O projeto americano foi, portanto, não governar o mundo diretamente, nem repassar essa tarefa às instituições internacionais, porém conceber um projeto de capitalismo global consistente com a tentativa de tornar ou manter outros Estados capitalistas, com instituições e práticas burocráticas, coercivas e jurídicas que assegurassem a acumulação de capital em todos os lugares.

Essa natureza dos EUA como império capitalista do século XX teria sido mal compreendida por Arrighi, ao entender que os EUA buscaram frustradamente construir um "Estado global" com ocupação territorial direta e defesa dos interesses do capital americano de forma estreita. A abertura de mercados e a extensão da competição faz parte da estratégia do Estado americano de garantir lucros e os interesses da classe capitalista americana como um todo. Para Panitch, as bases materiais do império americano estão longe de serem exauridas.

A capacidade do império informal estadunidense de "governar por meio de outros governos" ilumina a compreensão mais sofisticada e complexa do conceito de imperialismo nos dias atuais, relacionado à expansão internacional do capital. Essa concepção compreende um movimento histórico, indo além da noção inicial de imposição e ocupação territorial direta e percebendo como principal meio de dominação a coordenação da política em outros Estados, de modo a garantir a reprodução das Em Debat: Rev. Dig., ISSNe 1980-3532, Florianópolis, n. 7, p. 4-27, jan-jul, 2012. 
relações capitalista em nível global. Isto nos permite avançar na análise do papel dos chamados países emergentes nesta reprodução. Não somente a China, mas Brasil, Índia e outros estariam na órbita da expansão das relações capitalistas, reproduzindo também - e a seu modo peculiar - um lógica imperialista.

\section{Conclusão}

Este breve ensaio teve a finalidade de expor diferentes perspectivas sobre as tendências atuais de transformação na ordem mundial. Iniciamos com visões que não contemplam mudanças, mas sim ajustes e acomodações. Essas têm uma normatividade (ora implícita), que é a manutenção da própria ordem mundial sob dominação dos EUA. Buscamos, logo, apresentar algumas visões da teoria crítica e marxista sobre mudança e declínio da hegemonia estadunidense em direção a uma ordem plural, e o possível deslocamento do centro de poder e acumulação de capital para o Leste Asiático. Isto, por sua vez, é revidado por outros realistas e marxistas que, partindo de visões de mundo e métodos diferentes, chegam a conclusão de que a expansão econômica na Ásia (em especial da China) se situa dentro da estrutura de poder capitalista estadunidense, não implicando em uma "ameaça" a esse poder. A expansão global do capital é, desse modo, reproduzida "de forma tentacular" pelos países emergentes e intermediários, impulsionando um novo ciclo imperialista. Enquanto que a visão realista atenta para a ascensão e queda de poder e riqueza dos Estados, marxistas apontam para as contradições e implicações que isso abarca para as lutas sociais e de classes. Acreditamos que foi possível fornecer instrumentos para reflexão mais aprofundada sobre o conceito de mudança, que contribuam para ir além do senso comum, na tentativa de desconstrução de consensos. Esses representam supostas "necessidades" sobre crescimento econômico e caminhos para o "desenvolvimento" que ofuscam indagações sobre para quê e para quem crescer e se desenvolver, e de onde e para onde estamos "emergindo".

A realidade política na atual ordem mundial desafia o preceito da recorrência de guerras sistêmicas (inter-imperialistas, hegemônicas) para uma alteração do centro global de poder, podendo, assim, desafiar a noção da necessidade de um Estado ser uma potência militar para se tornar uma potência mundial. Esse desafio reflete um momento conjuntural (na medida em que a China ainda não pode concorrer com os EUA em 
termos militares), mas pode ser revertido, caso haja uma crescente militarização de países revisionistas, que decidam por um enfrentamento direto. Essa não tem sido a tendência dos países que hoje compõem os BRICS. O rápido crescimento econômico desses países, nas últimas décadas, não se traduziu, de forma automática, em poder militar e político. Eles procuram, conjunturalmente, ascender "dentro da ordem", por meio de maior participação nas instituições financeiras internacionais e fóruns multilaterais de decisão global, sem alterar substancialmente as regras e normas existentes. Com isso, não consideramos que a ascensão dos países BRICS configure uma tentativa de construção "contra-hegemônica" ou "anti-imperialista". Um Estado, mesmo que periférico e subalterno, não pode buscar construir uma "contra-hegemonia" se suas classes dominantes estiverem comprometidas com o próprio projeto de dominação existente. Embora suas estratégias de desenvolvimento persigam, em muitos casos, caminhos que objetivam "ultrapassar barreiras" e romper monopólios (científicos, industriais, comerciais, militares) criados pelas potências tradicionais, ${ }^{14}$ os países BRICS o fazem dentro da ordem capitalista, ocupando um lugar cada vez mais importante na reprodução expandida do capital global.

Concluímos que é necessário abranger e analisar a totalidade dos fenômenos, atores e relações sociais, para descortinarmos as tensões e desdobramentos das mudanças e movimentações de estruturas de poder. Nessa nova configuração, nossos estudos devem voltar-se ao papel das resistências e lutas sociais, de onde nascem e partem as mudanças concretas das relações sociais e das formas de vida, que são as bases para a criação de um novo mundo igualitário e justo.

\footnotetext{
${ }^{14}$ Especialmente a China vem aumentando, de forma significativa, sua participação na produção científica mundial. $\mathrm{O}$ indicador da participação em publicações e periódicos indexados internacionalmente demonstra que os países BRICS representavam juntos, em 1996, 9,1\% (frente 32\% dos EUA), mas saltaram para 21,8\% em 2010 (frente a queda para $22 \%$ na participação dos EUA). O motor desse crescimento é a China que, comparada com os demais BRICS, passou de 30\% em 1996 para mais de $60 \%$ em 2010, em termos de participação em publicações e periódicos indexados. A China foi a segunda maior investidora mundial em P\&D em 2009, cujo impulsor vem sendo o setor empresarial. Com isso, a China também vêm crescendo sua participação no registro do propriedade intelectual. Ver BRICS POLICY CENTER 2011b.
}

Em Debat: Rev. Dig., ISSNe 1980-3532, Florianópolis, n. 7, p. 4-27, jan-jul, 2012. 


\section{Referências}

ARRIGHI, Giovanni. The winding paths of capital. Interview by David Harvey. New Left Review 56, March-April 2009.

. Adam Smith em Pequim. São Paulo: Boitempo, 2008.

The three hegemonies of historical capitalism. IN: GILL, Stephen (ed.). Gramsci, historical materialism and International Relations. Cambridge University Press, 1993.

BRICS Policy Center. Desenvolvimento desigual e mudanças estruturais na economia mundial: a evolução da participação dos BRICS no PIB global, de 1900 a 2008 . Policy Brief, out 2011. Disponível em:

http://bricspolicycenter.org/homolog/uploads/trabalhos/940/doc/1786116251.pdf

. O desenvolvimento desigual na era do conhecimento: a evolução da participação dos BRICS na produção científica e tecnológica mundial, de 1996 a 2010. Policy Brief, dez 2011b. Disponível em: http://bricspolicycenter.org/homolog/uploads/trabalhos/3226/doc/1436536132.pdf

CHIN, Gregory. The emerging countries and China in the G20: reshaping global economic governance. Studia Diplomatica, Vol. LXIII, nr. 2-3, 2010

COX, Robert W. Entrevista realizada por Ana Garcia, Miguel Sá e Alessandro Biazzi em Cabbagetown, Toronto, maio de 2009 (manuscrito).

Social forces, states and world orders. Beyond international relations theory. In: LINKLATER, A. (Ed.). International Relations: critical concepts in political science. v. IV. London: Routledge, 2000 (1981).

FIORI, José Luis. O sistema interestatal capitalista no início do século XXI. In: FIORI; MEDEIROS; SERRANO (org.). O mito do colapso do poder americano. Rio de Janeiro: Record, 2008.

Globalização, hegemonia e império. In: TAVARES; FIORI (org.). Poder e

dinheiro: uma economia política da globalização. Petrópolis: Vozes, 1998. 
GILPIN, Robert. O desafio do capitalismo global. Rio de Janeiro, São Paulo: Record, 2004.

. US Power and the Multinational Corporation. New York: Basic Books, 1975.

HURREL, Andrew. Hegemonia, liberalismo e ordem global: qual o espaço para potências emergentes?. IN: HURREL et.al. Os BRICs e a ordem global. Rio de Janeiro: Editora FGV, 2009.

IKENBERRY, J.; WRIGHT, T. Rising powers and global institutions. A century foundation report. The Century Foundation, New York, 2008.

IKENBERRY, John. After victory. Institutions, strategic restraint, and the rebuilding of order after major wars. Princeton University Press, 2001.

. Getting hegemony right. The National Interest 63, Spring $2001 \mathrm{~b}$.

KEOHANE, Robert. Instituciones internacionales y poder estatal. Grupo Editor Latinoamericano, colección Estúdios Internacionales, 1993.

KINDLEBERGER, Charles. The world depression, 1929-1939. University of Califórnia Press, 1973.

PANITCH, Leo. Giovanni Arrighi in Beijing: an alternative to capitalism? Historical Materialism, Volume 18, Number 1, 2010.

PANITCH, Leo; GINDIN, Sam. Global capitalism and American Empire. Socialist Register 2004.

PATRICK, S. Irresponsable stakeholders? The difficulty of integrating rising powers. Foreign Affairs, November/December, 2010.

POULANTZAS, Nicos. State, power, socialism. London, New York: Verso, 2000.

WALLERSTEIN, Immanuel. The rise and future demise of the world capitalist system: concepts for comparative analysis. Comparative studies in society and history, vol. 16, nr. 4, Sept. 1974. 
WALLERSTEIN, Immanuel. The Three Instances of Hegemony in the History of the Capitalist World-Economy. IN: AKAHA, T. STILES K.W. (eds.). International Political Economy. Harper Collins. New York, 1991.

Mudando a geopolítica do mundo: 1945-2025. IN: SADER; SANTOS (coord.), MARTINS; VALENCIA (org.). A América Latina e os desafios da globalização. Rio de Janeiro: Ed. PUC-Rio; São Paulo: Boitempo, 2009.

WILSON, D; PURUSHOTHAMAN, R. Dreaming with BRICs: The path to 2050. Goldman Sachs Global Economics, paper nr. 99, 1st October 2003.

WOOD, Ellen Meinkins. Empire of Capital. 2nd ed. London, Verso, 2005. 